\title{
Influence Scope on the Existing Roads of a Certain Tunnel Underpass by Blasting Construction
}

\author{
Daohong Xia, Xianghui Deng, Rui Wang*, Yaoyao Meng \\ School of Civil Engineering and Architecture, Xi'an Technological University, Xi'an, China \\ Email address: \\ xiadaohong_737@163.com (Daohong Xia),dh_gl@163.com (Xianghui Deng), wangrui@xatu.edu.cn (Rui Wang), \\ 15291831068@163.com (Yaoyao Meng) \\ ${ }^{*}$ Corresponding author
}

\section{To cite this article:}

Daohong Xia, Xianghui Deng, Rui Wang, Yaoyao Meng. Influence Scope on the Existing Roads of a Certain Tunnel Underpass by Blasting Construction. International Journal of Transportation Engineering and Technology. Vol. 4, No. 3, 2018, pp. 50-58.

doi: $10.11648 /$ j.ijtet.20180403.11

Received: July 20, 2018; Accepted: September 5, 2018; Published: January 3, 2019

\begin{abstract}
In tunnel construction, blasting vibration has great influence on buildings and roads nearby. It is particularly important to discuss the influence scope of blasting vibration. This article focuses on the blasting vibration influence scope of the existing roads nearby through the blasting vibration velocity in-situ monitoring of key points with the case of blasting construction of Baohan highway project. The conclusions are as follows: the dominant frequency of blasting vibration is between $10-50 \mathrm{~Hz}$ during the monitoring of the tunnel blasting construction, so that the existing roads nearby will not resonate with blasting. Based on the results of this in-situ monitoring, for the general blasting construction, the vertical vibration velocity should be principally monitored because it is higher than the radial and tangential vibration velocity and it is significantly destructive to the buildings. To ensure the safety of structures and transportation of the existing roads, the blasting vibration velocity of key points is supposed to be $2.0 \mathrm{~cm} / \mathrm{s}$ for existing roads of the shallow-buried tunnel underpass with large cross-section and soft surrounding rock. Furthermore, the data shows that the influence scope of blasting vibration wave to the existing roads is about $30 \mathrm{~m}$, which is consistent with theoretical calculation results. Therefore, these results can provide references to the general tunnel constructions.
\end{abstract}

Keywords: Highway Tunnel, Blasting Construction, Blasting Vibration, Vibration Velocity, Vibration Frequency, Existing Roads, Influence Scope

\section{Introduction}

In recent years, with the rapid development of infrastructure construction in our country, the construction of tunnel and underground engineering has entered a large scale era of development. Newly built tunnel or underground engineering often needs to traverse the near existing building. Considering the technology and capital, NATM (New Austrian Tunneling Method) is still the main construction method used in our country. Therefore, the blasting excavation of newly built tunnel will affect the adjacent stratum and the architectural structure on the ground. If the setting of blasting parameters doesn't meet the requirements, the adjacent environment will be adversely affected by blasting vibration, such as violently shaking the ground, leading to artificial earthquakes, surface buildings' deformation, or even cracking. In order to ensure the safety of the construction and the personal safety of the people living near the blasting construction site, and reduce unnecessary accidental loss, it is necessary to determine the influence scope of blasting vibration.

So far, many scholars have researched the effect of tunnel blasting on adjacent buildings [1-6]. For examples, through collecting and analyzing blasting vibration data for a long time and observing the appearance of structural crack, Lou [7] presented that the permitted vibration velocity of ordinary residential buildings is $2 \mathrm{~cm} / \mathrm{s}$. Wang [8] monitored the blasting vibration of the existing building underpassed by a undersea tunnel, then analyzed and summarized the law of buildings' blasting vibration and the law of vibration velocity with the change of the floor. Based on the tunnel engineering blasting project of three work points in Line 3 of Qingdao 
Metro, Zhai [9] analyzed the distribution law of the maximum blasting vibration velocity, the main frequency and the velocity of key points by comparing the numerical simulation results with the measured results. Based on the practical engineering, Fan [10] studied the attenuation law of surface vibration velocity by combining numerical simulation with field test, then the noticeable influence area by blasting vibration was pointed out. By field test, $\mathrm{Fu}$ [11] monitored the blasting vibration velocity of the upper part of tunnel face and the side part of surrounding rock, then summed up the law of blasting vibration of them. Chen [12] monitored the blasting vibration velocity of the buildings adjacent to a certain tunnel exit of Chengkou-Wanyuan expressway, then pointed out that the vertical vibration velocity is faster than the tangential and radial velocity for buildings adjacent to the tunnel. Therefore, the vertical vibration velocity should be measured mostly. Zhang [13] summed up the latest research results about the attenuation and propagation law of blasting vibration wave, vibration-reducing control method and real-time remote blasting vibration testing technology in recent years, then predicted the corresponding model based on superposition and combination model of individual shot vibration, and discussed the evaluation criteria of safety for blasting vibration and summed up the realization of interference and vibration reduction by accurate delay of electronic detonator. In view of the present situation of few research achievements on the relationship between different blasting parameters and blasting excavation, and the relationship between the distance of surrounding buildings and blasting excavation, Qiao [14] tested and analyzed the particle vibration frequency and vibration velocity in the key position of the surface by field test based on a certain hydraulic tunnel engineering in Ningxia.

In summary, many domestic researches at present mainly focused on the effect of blasting vibration on adjacent buildings. However, the research on the influence scope of blasting vibration on existing road is basically blank when the new tunnel underpasses the existing road. Taking the blasting construction of a tunnel of Baoji-Hanzhong expressway underpassing the existing road for an example, the influence scope on the existing roads by blasting vibration is discussed.

\section{Method}

The influence of blasting vibration on existing roads can be visually displayed by the method of field blasting vibration test, and the specific parameters about influence scope can be obtained. Therefore, based on a tunnel construction, the influence scope on existing roads is discussed by the method of field blasting vibration test.

\subsection{General Situation of the Engineering}

A certain tunnel at Baoji-Hanzhong expressway is located at the south side of Wuguanhe Village in Wuguanyi Town of Liuba County and on the west side of the National Road 316. The distance between the tunnel and Wuguanhe Village is about $80 \mathrm{~m}$. The tunnel is designed by separating the left and right lines. The left line length of the tunnel is $420 \mathrm{~m}$ (ZK159+355 to ZK159+755) which is considered as short tunnel. The right line length of the tunnel is $509 \mathrm{~m}$ (YK159+335 to YK159+844) which is considered as medium tunnel. The tunnel applies a curved section with 3 centers of circles. The net width of architectural boundary is $14 \mathrm{~m}$, and the net height is $5 \mathrm{~m}$.

\subsubsection{Support Parameters}

The exit of the right line of the tunnel (YK159+781.09 YK159+818.25) through national road No.316, which is formed a 45 degree diagonal. Among it, the depth of YK159+801 is only $4.05 \mathrm{~m}$, which belongs to super shallow buried tunnel with fifth grade soil. The construction is difficult and the risk is high. Therefore, CRD method is used in the construction of newly built tunnel through national road No.316. Double $\Phi 159 \times 10 \mathrm{~mm}$ pipe roof advance support is used in the top of tunnel. Full-face excavation is used in the tunnel body, and the thickness of $\mathrm{C} 25$ shotcrete is $28 \mathrm{~cm}$ which is used in the primary support. Double $\Phi 8$ mesh reinforcement is used in the tunnel body with gird spacing of $20 \times 20 \mathrm{~cm}$. I $22 \mathrm{~b}$ steel frame is used in the full section with spacing of $50 \mathrm{~cm}$. $\Phi 22$ grouted rockbolt is used in the side wall with length of $4 \mathrm{~m}$, which are quincunx with spacing of $1 \mathrm{~m} \times 1 \mathrm{~m}$. The thickness of C30 reinforced concrete structure is $60 \mathrm{~cm}$ which is used in the secondary support. Grid steel frame is used in the secondary support to reinforce it. 4 \$22 main reinforcements, $\Phi 12$ stirrup with spacing of $20 \mathrm{~cm}$ and steel gird with spacing of $50 \mathrm{~cm}$ are used in the grid steel frame, which are set up at interval with steel arch of primary support. Spray anchor protection is used in center diaphragm and temporary. The thickness of shotcrete is $22 \mathrm{~cm}$ and 118 steel frame is used in it with spacing of $50 \mathrm{~cm}$. Leading conduit protection is used in center diaphragm. 11 grouted rockbolts which used early strength agent are used in the top of tunnel and its underside, and take one every $3.3 \mathrm{~m}$. Meanwhile, grouted rockbolts are also used in center diaphragm with spacing of $1 \mathrm{~m}$. The supporting design is shown in Figure 1.

Table 1. Blasting material.

\begin{tabular}{ll}
\hline Name of blasting material & Specifications \\
\hline \multirow{2}{*}{ Detonator } & Electric detonator(8\#) \\
Explosive & Plastic detonator(singular) \\
Type of cord & 2\#Rock emulsion explosive, Diameter $32 \mathrm{~mm}$, Length 20cm, Weight200g \\
\hline
\end{tabular}




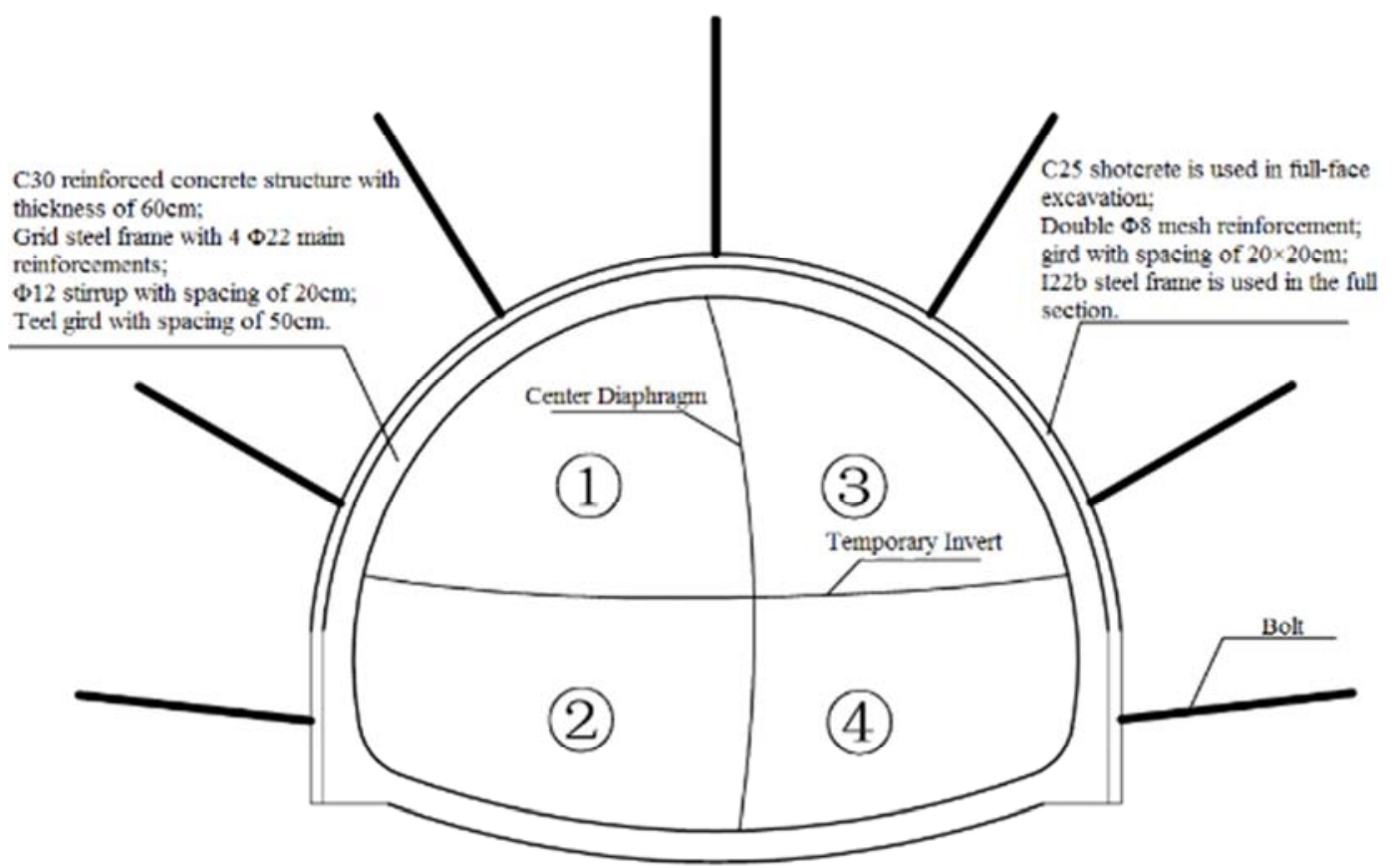

Figure 1. Supporting design.

\subsubsection{Blasting Design}

Smooth blasting is used in excavation of the existing roads of this tunnel underpass with footage of $1 \mathrm{~m}$. The choices of blasting material are shown in Table 1.

Sectional blasting construction is used in the design which is divided into 4 sections. The maximum quantity of explosive charge of single-stage priming of Part I is $8.75 \mathrm{~kg}$, the total charge is $17.8 \mathrm{~kg}$; The maximum quantity of explosive charge of single-stage priming of Part II is $9.25 \mathrm{~kg}$, the total charge is $15.75 \mathrm{~kg}$; The maximum quantity of explosive charge of single-stage priming of Part III is $5 \mathrm{~kg}$, the total charge is $12.8 \mathrm{~kg}$; The maximum quantity of explosive charge of single-stage priming of Part IV is $6 \mathrm{~kg}$, the total charge is $12 \mathrm{~kg}$. The specific blasting parameters are shown in Table 2, and the blast-hole arrangement is shown in Figure 2.

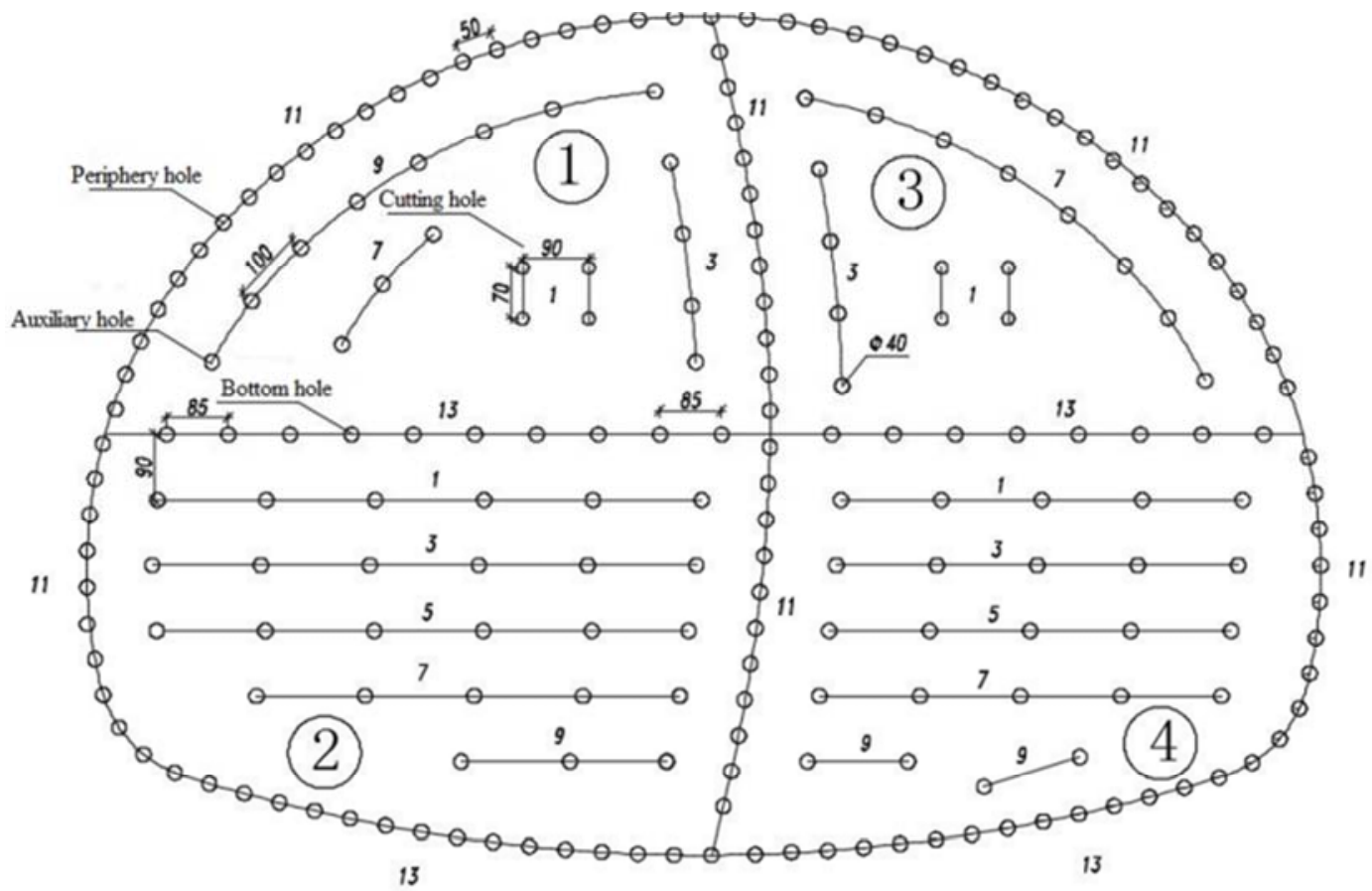

Figure 2. The layout of embrasure. 
Table 2. Blasting parameters.

\begin{tabular}{|c|c|c|c|c|c|c|}
\hline Position distribution & $\begin{array}{l}\text { Name of blast } \\
\text { hole }\end{array}$ & Number of hole & $\begin{array}{l}\text { Depth of hole } \\
\text { (m) }\end{array}$ & $\begin{array}{l}\text { the charge of a } \\
\text { blast hole }(\mathrm{kg})\end{array}$ & $\begin{array}{l}\text { Length of } \\
\text { stemming (m) }\end{array}$ & $\begin{array}{l}\text { Total charge } \\
\text { (kg) }\end{array}$ \\
\hline \multirow{4}{*}{ Part I } & Cutting hole & 4 & 1.2 & 0.70 & 0.50 & \multirow{4}{*}{17.80} \\
\hline & Auxiliary holes & 15 & 1.0 & 0.25 & 0.55 & \\
\hline & Periphery hole & 35 & 1.0 & 0.25 & 0.55 & \\
\hline & Bottom holes & 10 & 1.0 & 0.25 & 0.55 & \\
\hline \multirow{2}{*}{ Part II } & Auxiliary holes & 26 & 1.0 & 0.25 & 0.55 & \multirow{2}{*}{15.75} \\
\hline & Periphery hole & 37 & 1.0 & 0.25 & 0.55 & \\
\hline \multirow{4}{*}{ Part III } & Cutting hole & 4 & 1.2 & 0.70 & 0.50 & \multirow{4}{*}{12.80} \\
\hline & Auxiliary holes & 12 & 1.0 & 0.25 & 0.55 & \\
\hline & Periphery hole & 20 & 1.0 & 0.25 & 0.55 & \\
\hline & Bottom holes & 8 & 1.0 & 0.25 & 0.55 & \\
\hline \multirow{2}{*}{ Part IV } & Auxiliary holes & 24 & 1.0 & 0.25 & 0.55 & \multirow{2}{*}{12.00} \\
\hline & Periphery hole & 24 & 1.0 & 0.25 & 0.55 & \\
\hline Total & & & & & & 58.35 \\
\hline
\end{tabular}

\subsection{Field Test of Blasting Vibration}

To ensure the safety of traffic of the tunnel and the structure of the national road No.316 in the construction of the existing roads of this tunnel underpass, the field test of blasting vibration is carried out in the road surface. The specific operation and analysis are as follows.

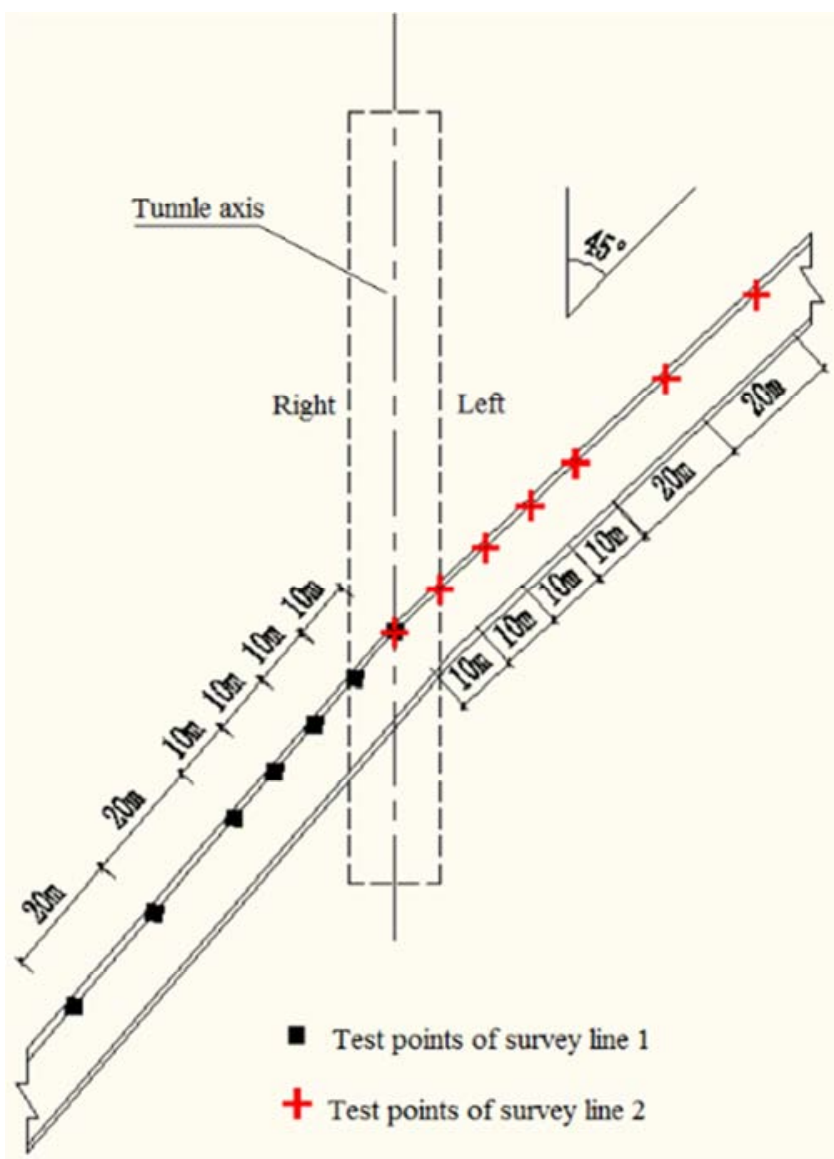

Figure 3. The layout of survey line.

\subsubsection{Test Point Layout}

Based on the engineering experience and the theoretical analysis, part I and part III are closest to the surface in the CRD method construction. Therefore, the tunnel blasting has larger influence on the upper existing road [15-17]. In summary, monitoring section of blasting vibration is only set up in the construction of part I and part III in the field test. Because of the newly built tunnel and the existing road are formed diagonal and clifftops and valley are located in both sides of the national road No.316, there are some limitations in the line layout which is vertical with tunnel axis. Therefore, the monitoring line is set up along the trend of national road No.316 in this field test [18-20].

Survey line 1 is set up along the Hanzhong direction of national road No.316. For part I, 7 test points are set up with the distance from tunnel axis of $0 \mathrm{~m}, 10 \mathrm{~m}, 20 \mathrm{~m}, 30 \mathrm{~m}, 40 \mathrm{~m}$, $60 \mathrm{~m}$ and $80 \mathrm{~m}$. Survey line 2 is set up along the Liuba direction of national road No.316. For part II, 7 test points are set up with the distance from tunnel axis of $0 \mathrm{~m}, 10 \mathrm{~m}$, $20 \mathrm{~m}, 30 \mathrm{~m}, 40 \mathrm{~m}, 60 \mathrm{~m}$ and $80 \mathrm{~m}$. The layout of survey line is shown in Figure 3.

\subsubsection{Test Method}

(1) Positioning of measuring points

In order to accurately measure the location relationship between test point and blasting surface, measuring coordinate is ascertained by GPS, meanwhile, spikes are used to badge on the surface of national road. The GPS positioning of measure point is shown in Figure 4, and the layout of measure point is shown in Figure 5.

(2) Blasting vibration monitoring

Blasting vibration measurement system consists of TCS-B3 three direction vibration sensor, low noise shielded cable, TC-4580 blasting vibration recorder, and the computer, as shown in Figure 6.

Through the field test, the maximum velocity of tunnel blasting vibration is $8 \mathrm{~cm} / \mathrm{s}$, and the blasting period is about $1 \mathrm{~s}$. In order to ensure the effective acquisition of signals and avoid to mistake the instrument by signal interference, trigger level value is set to $0.4 \mathrm{~cm} / \mathrm{s}$. In order to ensure the integrity of monitoring waveforms, the period of blasting vibration recorder is set to $2 \mathrm{~s}$. The delay is set to $-100 \mathrm{~ms}$ because $\theta$ f the waveform is not more than $0.1 \mathrm{~s}$ before the data is recorded by blasting vibration recorder. Meanwhile, in order to ensure that the waveform is not distorted, sampling frequency is set to 32 $\mathrm{KHz}$ in this field test. 
Before the test, gypsum slurry with water cement ratio of $1: 35$ is used in fixing the sensor on the test point. The $X$ axis of the sensor is parallel to the blasting surface, the $\mathrm{Y}$ axis of the sensor points to the blasting face direction, and the $\mathrm{Z}$ axis of the sensor is perpendicular to the horizontal plane. The instruments installation is shown in Figure 7.
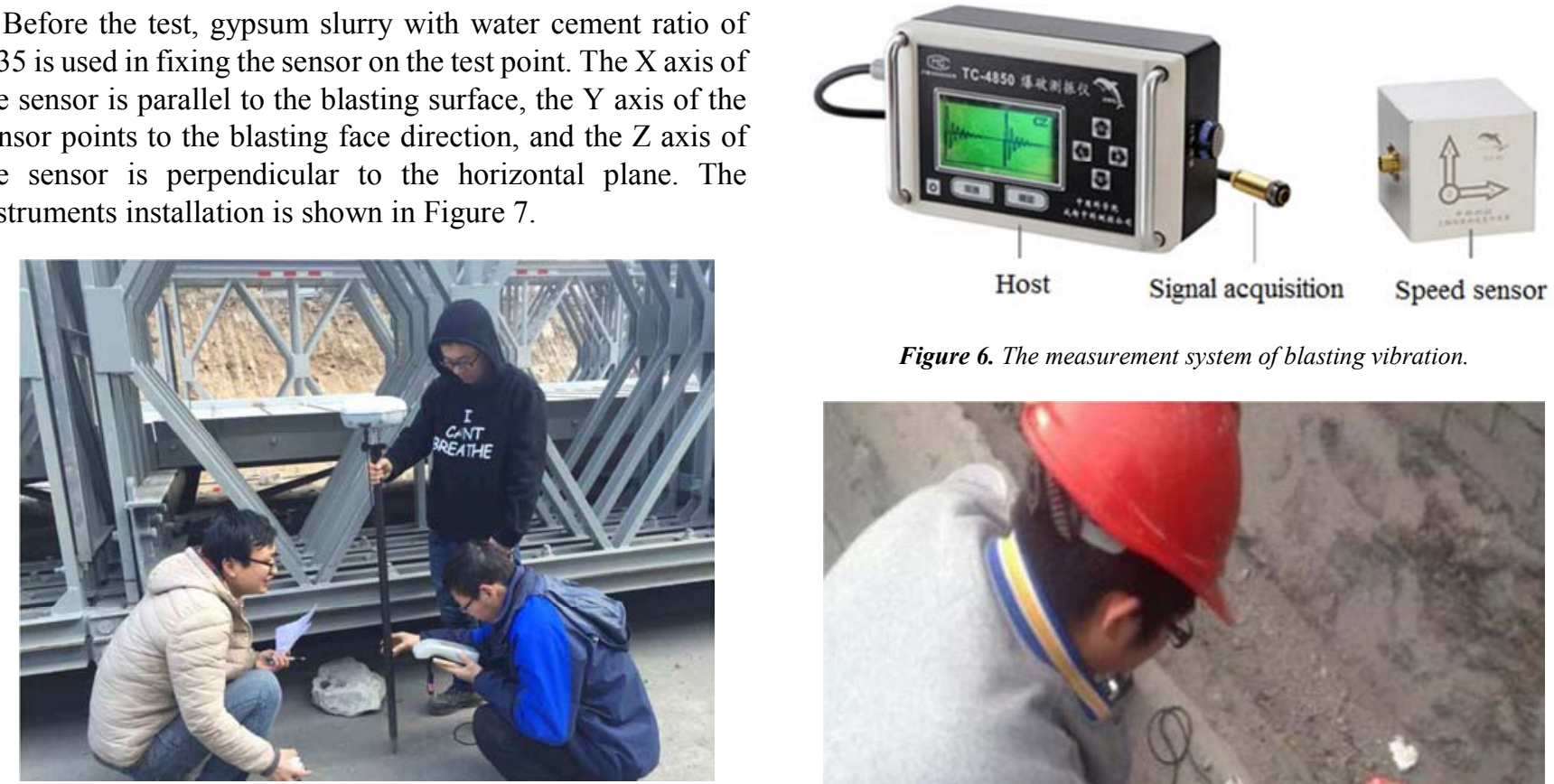

Figure 6. The measurement system of blasting vibration.

Figure 4. The GPS positioning of measure point
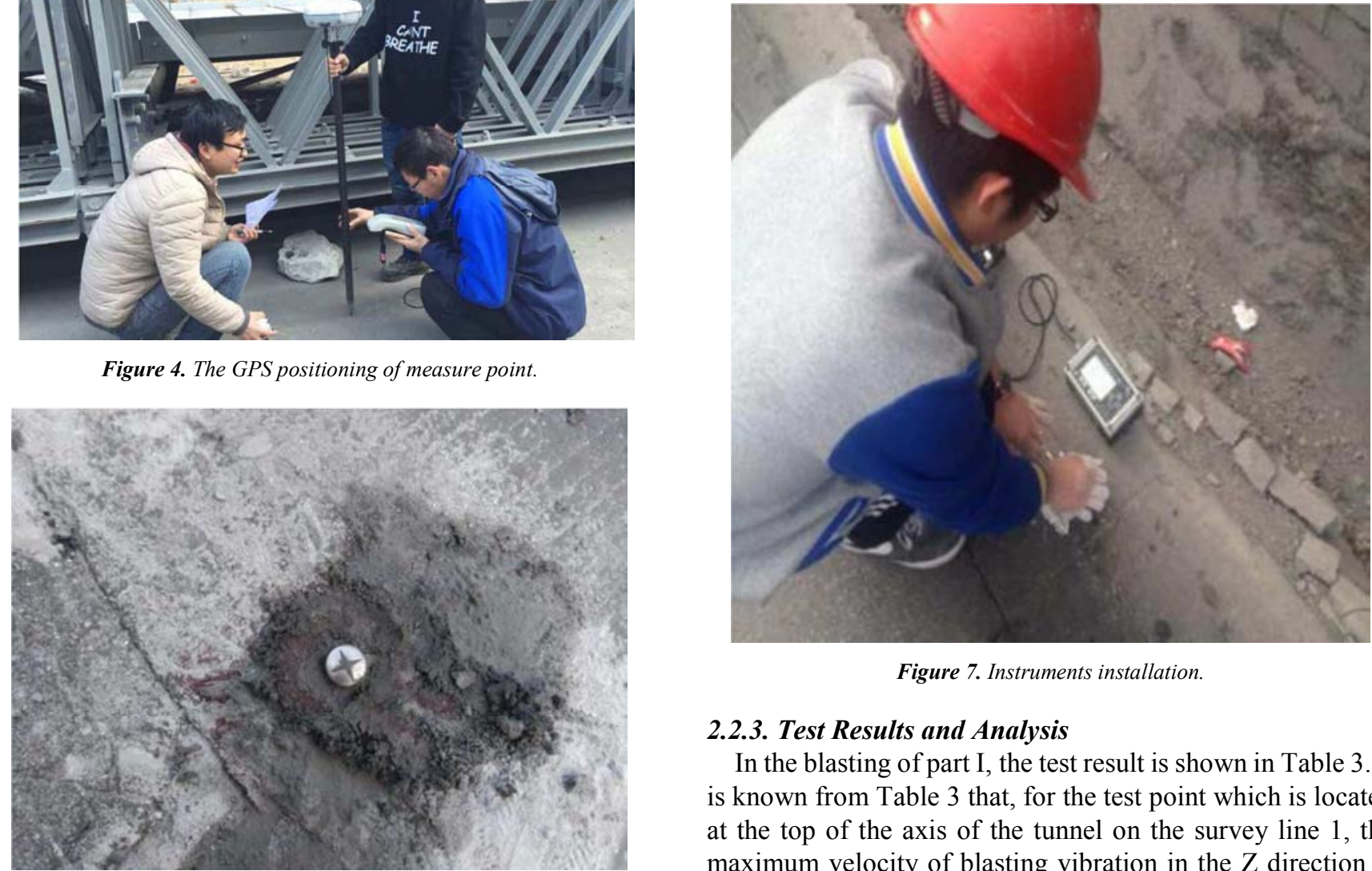

Figure 7. Instruments installation.

\subsubsection{Test Results and Analysis}

In the blasting of part I, the test result is shown in Table 3. It is known from Table 3 that, for the test point which is located at the top of the axis of the tunnel on the survey line 1 , the maximum velocity of blasting vibration in the $\mathrm{Z}$ direction is $8.250 \mathrm{~cm} / \mathrm{s}$. The vibration waveform is shown in Figure 8 .

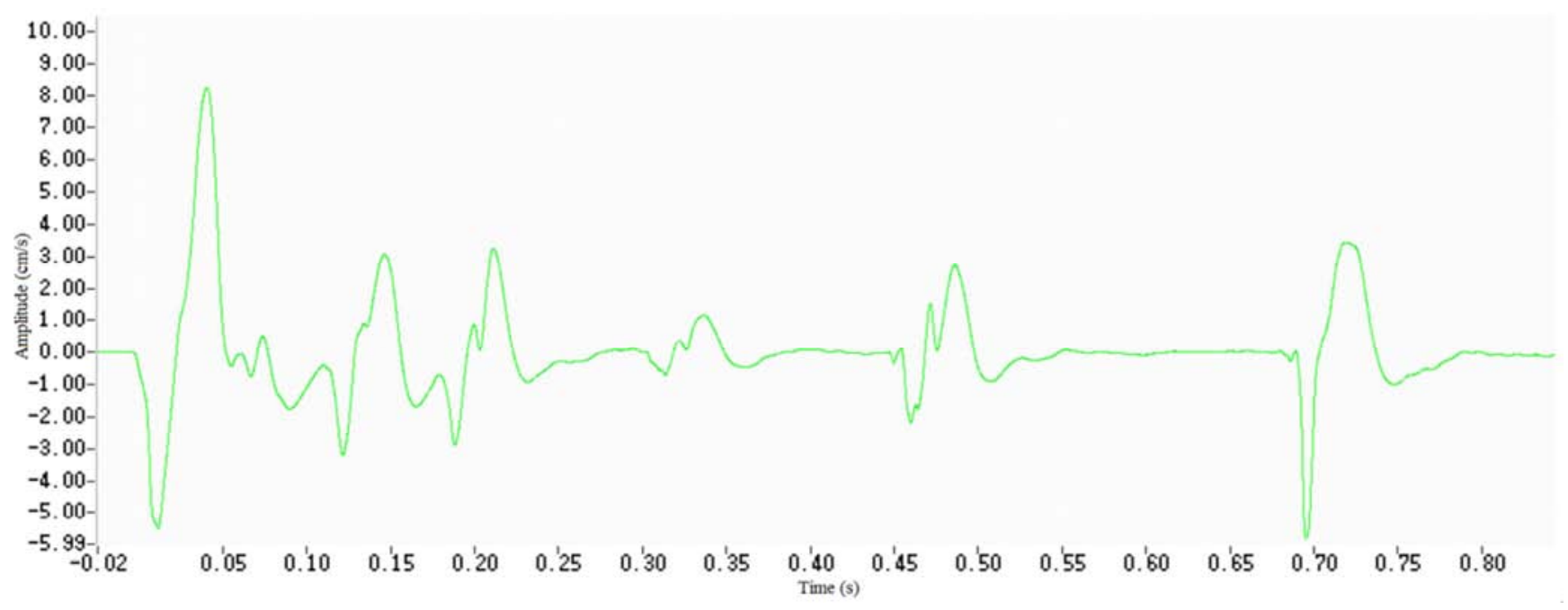

Figure 8. Blasting vibration wave of $Z$ direction. 
Table 3. The blasting vibration results of the measuring point on the first survey line.

\begin{tabular}{lllllllll}
\hline \multicolumn{2}{l}{ Distance from detonating source } & $\mathbf{0 m}$ & $\mathbf{1 0 m}$ & $\mathbf{2 0 m}$ & $\mathbf{3 0 m}$ & $\mathbf{4 0 m}$ & $\mathbf{6 0 m}$ & $\mathbf{8 0 m}$ \\
\hline \multirow{3}{*}{ Maximum value $(\mathrm{cm} / \mathrm{s})$} & $\mathrm{X}$ & 3.246 & 1.964 & 1.624 & 1.248 & 0.537 & 0.204 & $<0.4$ \\
& $\mathrm{Y}$ & 4.429 & 4.851 & 2.143 & 1.677 & 0.664 & 0.394 & $<0.4$ \\
& $\mathrm{Z}$ & 8.250 & 7.966 & 2.873 & 1.862 & 0.879 & 0.462 & $<0.4$ \\
Main frequency(Hz) & $\mathrm{X}$ & 21.220 & 24.768 & 28.436 & 21.773 & 18.445 & 30.255 & - \\
& $\mathrm{Y}$ & 10.855 & 15.504 & 23.457 & 24.319 & 23.176 & 32.451 & - \\
Time & $\mathrm{Z}$ & 16.878 & 17.167 & 22.316 & 27.558 & 27.323 & 26.154 & - \\
$(\mathrm{ms})$ & $\mathrm{X}$ & 3.463 & 2.663 & 5.548 & 5.917 & 6.424 & 9.320 & - \\
& $\mathrm{Y}$ & 4.169 & 4.250 & 6.246 & 7.133 & 7.751 & 7.328 & - \\
\hline
\end{tabular}

In the blasting of part III, the test result is shown in Table 4. It is known from Table 4 that, for the test point which is located at the top of the axis of the tunnel on the survey line 2 , the maximum velocity of blasting vibration in the $\mathrm{Z}$ direction is $6.717 \mathrm{~cm} / \mathrm{s}$. The vibration waveform is shown in Figure 9.

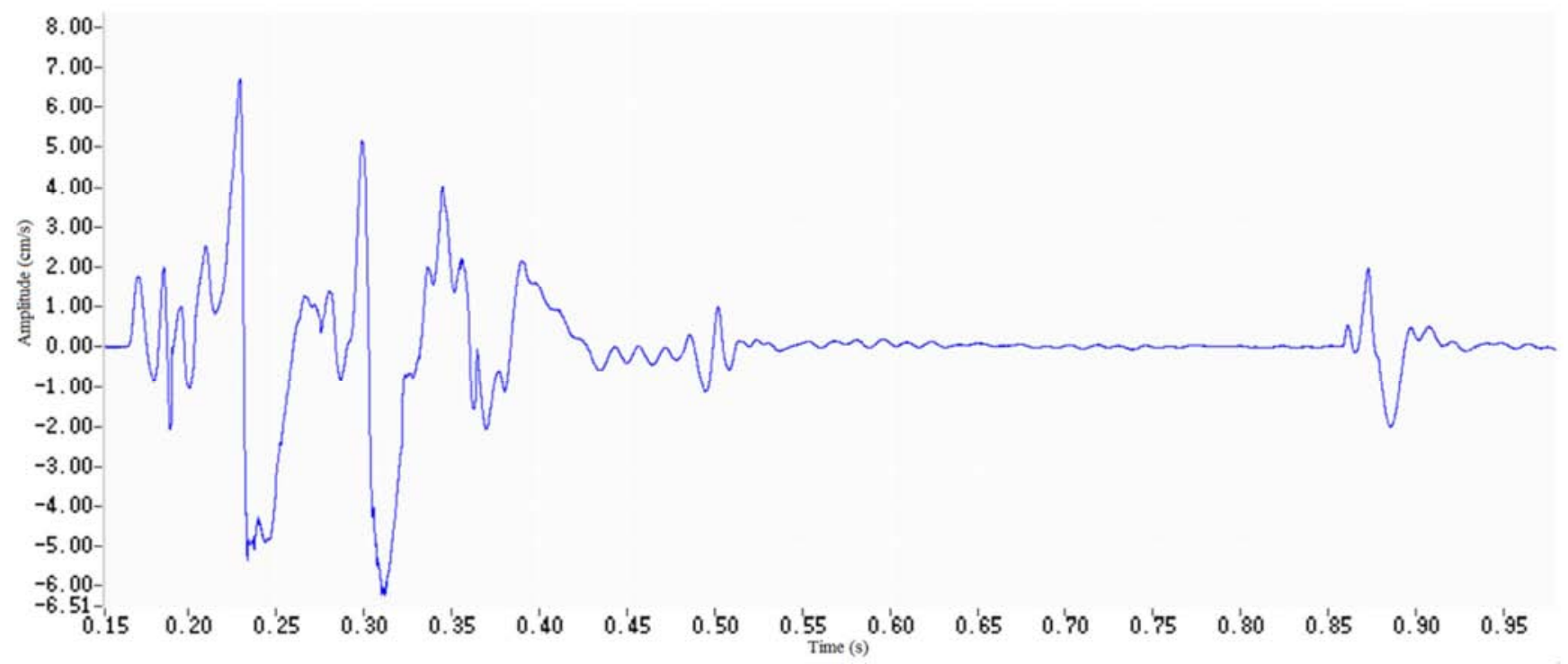

Figure 9. Blasting vibration wave of $Z$ direction.

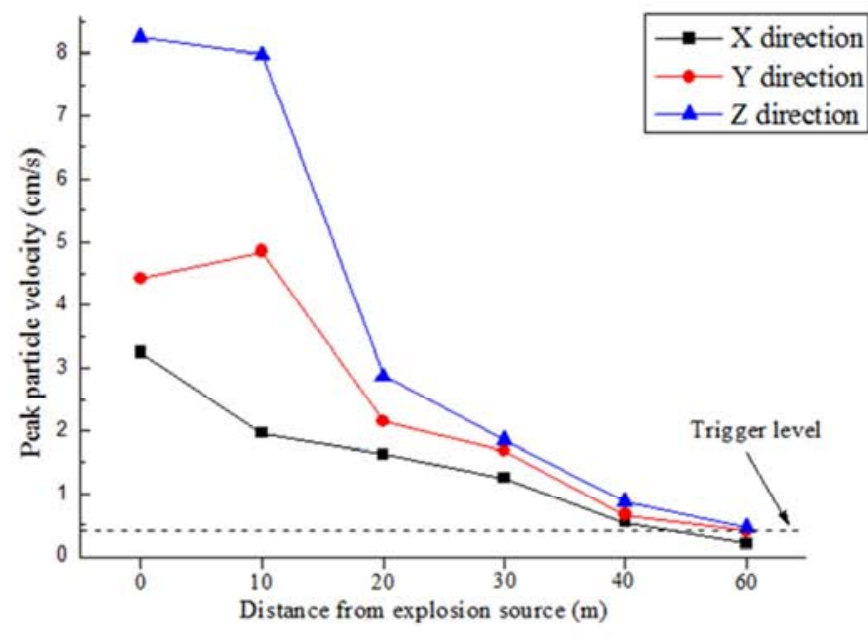

a. The results of line 1

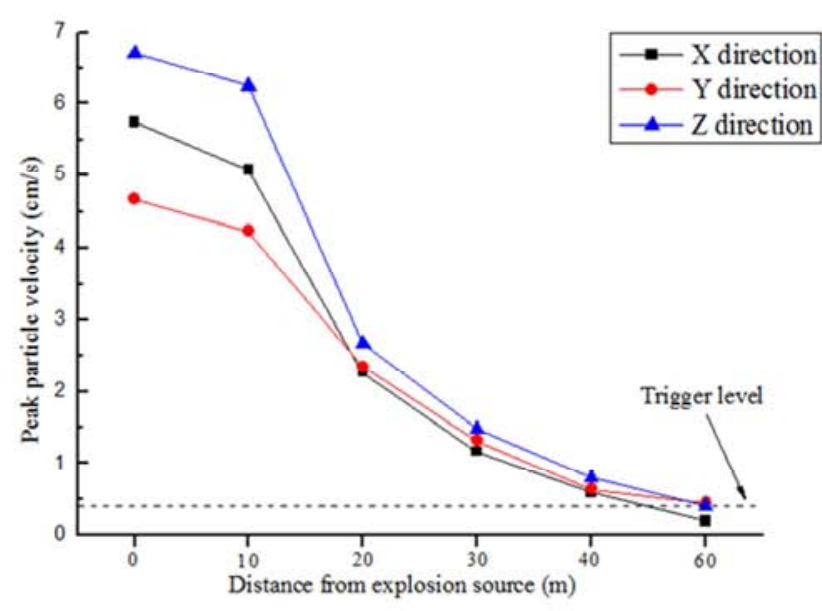

b. The results of line 2

Figure 10. The blasting vibration results. 
Table 4. The blasting vibration results of the measuring point on the second survey line.

\begin{tabular}{|c|c|c|c|c|c|c|c|c|}
\hline \multicolumn{2}{|c|}{ Distance from detonating source } & \multirow{2}{*}{$\begin{array}{l}\mathbf{0 m} \\
5.749\end{array}$} & \multirow{2}{*}{$\begin{array}{l}\mathbf{1 0 m} \\
5.074\end{array}$} & \multirow{2}{*}{$\frac{\mathbf{2 0 m}}{2.268}$} & \multirow{2}{*}{$\frac{30 \mathrm{~m}}{1.169}$} & \multirow{2}{*}{$\frac{\mathbf{4 0 m}}{0.593}$} & \multirow{2}{*}{$\frac{60 \mathrm{~m}}{0.193}$} & \multirow{2}{*}{$\begin{array}{l}\mathbf{8 0 m} \\
<0.4\end{array}$} \\
\hline & $\mathrm{X}$ & & & & & & & \\
\hline Maximum value $(\mathrm{cm} / \mathrm{s})$ & $\mathrm{Y}$ & 4.671 & 4.236 & 2.349 & 1.311 & 0.637 & 0.439 & $<0.4$ \\
\hline & $\mathrm{Z}$ & 6.717 & 6.245 & 2.678 & 1.487 & 0.801 & 0.403 & $<0.4$ \\
\hline \multirow{3}{*}{ Main frequency $(\mathrm{Hz})$} & $\mathrm{X}$ & 29.466 & 25.645 & 28.457 & 27.468 & 19.581 & 29.851 & - \\
\hline & $\mathrm{Y}$ & 44.818 & 32.457 & 35.546 & 33.421 & 22.153 & 28.169 & - \\
\hline & $\mathrm{Z}$ & 17.758 & 19.356 & 24.684 & 29.634 & 39.451 & 44.326 & - \\
\hline \multirow{2}{*}{$\begin{array}{l}\text { Time } \\
\text { (ms) }\end{array}$} & $\mathrm{Y}$ & 3.048 & 2.945 & 3.126 & 5.572 & 5.178 & 7.225 & - \\
\hline & Z & 2.297 & 4.054 & 4.264 & 5.218 & 6.523 & 7.328 & - \\
\hline
\end{tabular}

Because of the equipment distributing far distance, no data are collected with the distance of $80 \mathrm{~m}$ from the instrument on the survey line 1 and 2 . In other words, the vibration velocity of the particle is less than $0.4 \mathrm{~cm} / \mathrm{s}$ at $80 \mathrm{~m}$ So the blasting vibration recorder isn't triggered to record data. According to the survey results, the peak particle velocities in $\mathrm{X}, \mathrm{Y}$ and $\mathrm{Z}$ directions of each measuring point are used to draw the velocity-distance curves, which are shown in Figure 10.

\section{Result}

As is shown in the above two monitoring results,

(1) It is known from Table 3 and 4 that, the maximum velocity of blasting vibration appears in the $Z$ direction of the test point above the tunnel axis, and the velocity is $8.250 \mathrm{~cm} / \mathrm{s}$ and $6.717 \mathrm{~cm} / \mathrm{s}$ respectively on the survey line 1 and 2 . For survey line 1 , the velocity of $\mathrm{Z}$ direction is obviously larger than that of $X$ direction and $Y$ direction at $0 \mathrm{~m}, 10 \mathrm{~m}, 20 \mathrm{~m}$, $30 \mathrm{~m}, 40 \mathrm{~m}, 60 \mathrm{~m}$. For survey line 2 , the velocity of $\mathrm{Z}$ direction is also larger than that of $\mathrm{X}$ direction and $\mathrm{Y}$ direction at $0 \mathrm{~m}$, $10 \mathrm{~m}, 20 \mathrm{~m}, 30 \mathrm{~m}, 40 \mathrm{~m}$. It is shown that the vertical vibration velocity is larger than the radial velocity and the tangential velocity for the surface of existing road in this tunnel blasting. Meanwhile, according to the practical experience of the engineering, the vertical longitudinal wave is more easily to cause pavement cracking at the time of blasting vibration. Therefore, vertical vibration velocity should be mainly surveyed for blasting vibration monitoring in such a similar engineering situation.

(2) As is shown in the monitoring results, the minimum main frequency of seismic wave produced by tunnel blasting is $10.855 \mathrm{~Hz}$, and the maximum is $44.818 \mathrm{~Hz}$. The scope of change in main frequency is $10 \sim 50 \mathrm{~Hz}$. Based on the existing research results [21], the natural frequency of common buildings is all below $10 \mathrm{~Hz}$. Therefore, the existing road will not resonate with the blasting vibration wave.

(3) The monitoring results show that, the farther the distance from the top axis of the tunnel is, the smaller the blasting vibration velocity of each point is. The maximum vibration velocity is less than $0.4 \mathrm{~cm} / \mathrm{s}$ at $80 \mathrm{~m}$ from the blasting tunnel face, which has no effect on the safety of the existing road. According to the safe and permitted standard of blasting vibration in GB6722-2014, Safety regulations for blasting [22], for common civil buildings, such as national road, when the main frequency of blasting vibration is $10 \sim 50 \mathrm{~Hz}$, blasting vibration velocity of key points is $2.0 \sim 2.5 \mathrm{~cm} / \mathrm{s}$. This engineering considers the importance of national road No.316. Meanwhile, the condition of surrounding rock is poor, the buried depth is shallow, and the span is long on the existing roads of this tunnel underpass. In order to ensure the safety of the newly built tunnel and the existing road, the maximum velocity of the peak vibration of the particle is $2.0 \mathrm{~cm} / \mathrm{s}$ which is lower limit. Under this standard, compared with the result of this blasting test, it is known that the influence scope of the blasting vibration wave on existing roads is less than $30 \mathrm{~m}$. Surface settlement observation should be conducted in the scope of this influence. If the deformation rate and cumulative deformation are no more than the security alert value, the safety of the road can be explained.

\section{Discussion}

Based on Sadaovsk Formula, the influence scope of blasting vibration can be obtained [23-25]. Sadaovsk Formula is as follows:

$$
R=\left(\frac{K}{V}\right)^{\frac{1}{\alpha}} \cdot Q^{\frac{1}{3}}
$$

Where $R$ is allowable safety distance of blasting vibration (m); $Q$ is quantity of explosive, which is total explosive charge for simultaneous blasting and maximum charge of explosives for delay blasting $(\mathrm{kg}) ; V$ is blasting vibration velocity of key points for the location of the protected object $(\mathrm{cm} / \mathrm{s}) ; K, \alpha$ are coefficient and attenuation index related to the topography and geological conditions between the blasting points and the protected objects, which can be selected according to the standard or determined by field test.

When CRD method is used in this engineering, part I and part III belong to upper half which is closer to the surface. It is greatly influenced by blasting vibration. Therefore, this article only discusses allowable safety distance of blasting for part I and part III.

The surrounding rock grad in the construction stage is V grade, which is more broken soft rock. Therefore, according to the lower limit of standard, $\mathrm{K}=350, \alpha=2.0$. Based on the field test, blasting vibration velocity of key points is $2.0 \mathrm{~m} / \mathrm{s}$; maximum charge of explosives of part I is $8.75 \mathrm{~kg}$; maximum charge of explosives of part III is $8.75 \mathrm{~kg}$. By substituting these 
values in Formula 1, we can obtain that the influence scope by blasting vibration of part I is $27.21 \mathrm{~m}$, and that of part III is $22.61 \mathrm{~m}$. This is relatively consistent with the field test results. In other words, it is safe and reliable that the safety distance is set to $30 \mathrm{~m}$.

\section{Conclusion}

Based on a certain tunnel underpass at Baoji-Hanzhong expressway of national road No.316, a site test scheme for blasting vibration is formulated. According to the field test results, the influence scope by blasting construction on existing roads and vibration allowable safety velocity of key points of surface are proposed. The main conclusions are as follows.

(1) From the blasting test, the main frequency of blasting vibration is $10 \sim 50 \mathrm{~Hz}$ for tunnel construction, which will not resonate with the existing road. Meanwhile, the vertical vibration velocity is larger than the radial velocity and the tangential velocity for the surface of existing road. However, the vertical vibration is particularly notable to the destruction of the building. Therefore, vertical vibration velocity should be mainly surveyed for blasting vibration monitoring in such a similar engineering situation.

(2) In the blasting construction of the existing roads of newly built tunnel underpass, tunnel depth, section, surrounding rock classification and surrounding environment should be comprehensive considered to obtain the vibration allowable safety velocity of key points. According to the field test results, the importance of engineering and engineering geological conditions, it is proposed that vibration allowable safety velocity of key points of surface is $2.0 \mathrm{~cm} / \mathrm{s}$, which can ensure the safety of existing road structure and traffic. Furthermore, based on measured results and theoretical analysis, it is obtained that the influence scope on existing roads by blasting construction is $30 \mathrm{~m}$.

The research results in this paper can provide a theoretical basis for blasting design and construction of similar engineering situation.

\section{Acknowledgements}

This research was financially supported by the National Natural Science Foundation of China (51679199); the Natural Science Basic Foundation by Shaanxi Province (2017JM5136); the Key Research and Development Program by Shaanxi Province (2018SF-391); the Key Laboratory Program by Shaanxi Provincial Science (2014SZS15-Z01); the Housing and Urban-Rural Construction Foundation by the Housing and Urban-Rural Department of Shaanxi Province (2017-K55); the Scientific Research Program for Technology of Highway Construction and Maintenance Technology of National Transportation Industry Key Laboratory (KLTLR-Y14-15) and Technology Innovation and the Research Program sponsored by Xi'an Technological University President Fund (XAGDXJJ16003).

\section{References}

[1] C Wenshu, Y Yaofeng and L Junqin (2008). The Evaluation of the Adjacent Structures under the Tunnel Blast Construction. Industrial Building 38(S1), 1019-1021.

[2] J Deyi, H Yabin, R Song, L Fusheng and C Yu (2008). Study on the Influence of Urban Large-span Tunnel Blasting on Ground Buildings. China Safety Science Journal 18(7), 99-104.

[3] Z Tao, Y Guangming, X Bin, J Zhengbo and Y Xinxin (2011). Safey Evaluation of the Ground Buildings under the Tunnel Blasting Vibration. Journal of Qingdao Technological University 32(5), 36-40.

[4] H Aijun (2010). Seismic Effects of Blasting Vibration in Metro Tunnel Excavation. Sichuan Building Science 36(3), 154-157.

[5] W Xing, C Xiren, L Qijian and Z Shuming (2009). Safety Influence of Shallow-buried Tunnels on the Nearby Buildings and Reinforcing Measures to be taken. Journal of Safety and Environment 9(4), 111-115.

[6] M Qi, Q Mingcan, X Jianfeng, L Yongjun and Z Xiujuan (2013). Safety Analysis of the Damage to Close Buildings Posed by Tunnel Blast Vibration. Guangdong Chemical Industry 40(16), 82-83.

[7] L Jianwu (2000). Analysis on Vibration Response and Damage of Low-rise Residential House Caused by Blasting. Blasting 17(4), 8-13.

[8] W Li and W Hailiang (2012). Influence of Different Direction Vibration Peak Velocity of Tunnel Blasting on Building. Blasting 29(4), 6-9.

[9] Z Caiya, L Anlong, L Tao and S Yu (2014). Vibration Propagtion of Tunnel Blasting in Granite Areas. Journal of Engineering Geology 22(5), 824-831.

[10] F Haobo, Q Junling, X Yongli and G Chunxia (2016) Blast-induced Ground Vibration from Tunnel Undercrossing a Village. Journal of PLA University of Science and Technology (National Science Edition) 17(3), 209-214.

[11] F Hongxian, Z Yong, X Jinshui and H Yongbing (2011). Study of Blasting Vibration Test of Area Near Tunnel. Chinese Journal of Rock Mechanics and Engineering 30(2), 335-340.

[12] C Zhongxue, H Baiwan and L Yanbo (2012). Research on Vibration and Antivibration which Blasting Vibration Imposed on Building near to Tunnel. Earthquake Resistant Engineering and Retrofitting 34(04), 73-75.

[13] Z Zhiyi, Y Nianhua, L Wenbo, Z Gen and S Fuqiang (2013). Progress of Blasting Vibration Control Technology in China. Blasting 30(2), 25-32.

[14] Q Xiong, C Jianxun, W Mengshu and W Xiaoxing (2016). Experimental Analysis of Influence of Blasting Vibration in a Hydraulic Tunnel on Surrounding Buildings. China Earthquake Engineering Journal 38(4), 504-509.

[15] C Jianguo. Techniques for Passenger-dedicated Railway Tunnel Underpassing Existing Expressway. Modern Tunnelling Technology 47(6), 62-66.

[16] W Kediao and D Rensheng (2009). Technology for Monitoring in Construction of Undergoing through Existing Tunnel. Railway Survey 6, 60-62. 
[17] X Yiming, Z Mingxin, H Guoping. and L Jiahua (2016). Analysis of Vibration Impact Caused by Relief Channel Blasting on Existing High-speed Railway Tunnel. Railway Standard Design 60(3), 97-101.

[18] Z Mingdong (2005). The Controlled Blasting of Dapingshan Tunnel Undergoing through Existing Expressway. West-China Exploration Engineering 109(6), 122-124.

[19] Z Junjie, B Deyong, G Yanfeng and Z Yi (2006). Research on Construction Control Technology for Railway Tunnel Underneath Passing Existing Expressway Tunnel. Journal of Railway Engineering Society 8, 80-84.

[20] Z Zhiyong (2008). Blasting Methods of Shallow Buried Tunnel Passing through the Present Railroad. Railway Construction Technology 4, 69-74.
[21] S Jumin, Z Xiyuan, G Xiaowang and L Jingbo (2000). Anti-knock Engineering. Beijing: Chinese Building Industry Press.

[22] GB6722-2014, Safety regulations for blasting. Beijing: Standards Press of China, 2014.

[23] X Hailiang, Z Jichun, Y Hong and Z Xinwu (2007). Investigation on Calculating Formula of Vibration Velocity in Drilling Blasting and Its Simplification. Journal of Tongji University (Natural Science) 35(7), 899-903+914.

[24] X Hailiang, Z Jichun and G Jianqun (2003). Investigation on Formula of Predicting the Particle Vibration Velocity in Drilling Blasting. Blasting 20(3), 75-78.

[25] G Keshui (2003). Discussion on Calculation Methods for Blasting Vibration. Exploration Engineering S1, 299-300. 